\title{
Does frequency matter for intraday technical trading?
}

\author{
Michael Frömmel*, Kevin Lampaert \\ Ghent University, Department of Financial Economics, Sint-Pietersplein 5, 9000 Ghent, Belgium
}

\section{A R T I C L E I N F O}

\section{Article history:}

Received 22 December 2015

Revised 22 March 2016

Accepted 10 April 2016

Available online 11 April 2016

\section{JEL Classifications:}

G11

G14

G17

\section{Keywords:}

Foreign exchange

Technical analysis

Intraday

Emerging markets

\begin{abstract}
A B S T R A C T
We examine the impact of frequency on the intradaily profitability of more than 8000 technical trading rules using an extensive and unexplored sample of intraday data for the Russian Ruble-US Dollar foreign exchange market. The results indicate that technical trading profits seem much more present on a higher frequency basis. The adjustment for real, rather than estimated transaction costs wipes away most of the profits. However, we do find evidence that technical trading rules applied at a sufficiently high frequency generate superior returns when the central bank conducts a stabilizing exchange rate policy.
\end{abstract}

(c) 2016 Elsevier Inc. All rights reserved.

\section{Introduction}

The use of technical analysis, which uses past prices to guide trading decisions, is strongly contested by many academics (Malkiel, 1996) due to its head to head position with the efficient market hypothesis. Nevertheless, surveys show that technical analysis still is a popular technique in the financial industry, particularly in the foreign exchange market. In a seminal paper, Taylor and Allen (1992) found that 94\% of foreign exchange dealers in London used some form of technical analysis over short horizons which is confirmed by subsequent research (Menkhoff, 1997; Lui and Mole, 1998; Oberlechner, 2001; Cheung and Chinn, 2001; Cheung et al., 2004; Gehrig and Menkhoff, 2006; Menkhoff and Taylor, 2007). The fact that technical analysis is most heavily used on the foreign exchange market, is surprising at first sight, since this market is dominated by professional traders. However, the market shows various characteristics making it prone for technical analysis. First, the share of short-term (inter-dealer) trading is significantly higher than in other financial markets (Lyons, 2001). Second, there is a plethora of competing fundamental models and this lack of a consensus model may be a reason for the popularity of technical analysis on foreign exchange markets (Menkhoff and Taylor, 2007). Third, central bank interventions on the foreign exchange market may produce exploitable technical trading opportunities (Saacke, 2002). Fourth, the forthcoming profits from the use of technical trading rules and exchange rate fluctuations are self-reinforcing (Schulmeister, 2006).

\footnotetext{
Financial support by the Research Foundation Flanders - Fonds Wetenschappelijk Onderzoek is gratefully acknowledged (Grant no. G072113N). We further thank the participants of the Infiniti 2015 conference and the Institutional Investors and Emerging Market Finance conference 2016 for their helpful comments and suggestions.

* Corresponding author.

E-mail addresses: Michael.Froemmel@UGent.be (M. Frömmel), Kevin.Lampaert@UGent.be (K. Lampaert).
} 
The empirical literature highlights that technical trading rules are more profitable in emerging economies and on the foreign exchange market. Park and Irwin (2007) report almost 100 'modern' studies between 1988 and 2004 and find annual net profits of $10-30 \%$ for emerging markets and $5-10 \%$ for the foreign exchange market. The former could be attributed to lower market efficiency in emerging markets due to less intense competition, a lower number of market participants (Lo, 2004) and the lack of sufficient publicly available information (Bessembinder and Chan, 1995). More recently, Neely and Weller (2013) argue that trading rule returns in foreign exchange markets remain significant but shifted towards emerging markets. Also Chang et al. (2014) find evidence for the profitability of moving average trading rules for emerging stock markets. Another argument highlights that the practice could have had merit in any market but that its profitability decreased over time (Olson, 2004; Qi and Wu, 2006; Schulmeister, 2009) driven by a continuous increase in market efficiency or to environmental changes suggested by the adaptive market hypothesis (Lo, 2004).

Despite the reported use on short term technical trading (Menkhoff and Taylor, 2007), the majority of empirical research is based on daily or lower frequency data, whereas only 6 out of 92 reported modern studies used intraday data (Park and Irwin, 2007). Furthermore, none of these studies examine the effect of trading frequency on technical trading profitability. Hence, this paper contributes at least fourfold to the literature by performing an intraday study on the Russian RubleUS Dollar currency market. First, we analyze the profitability and hence focus on an emerging economy's exchange rate, therefore combining the two most promising markets in terms of profitable technical analysis. Second, our data set covers a long time span of more than ten years and is tick-by-tick data, thus collected at the highest possible frequency. Therefore the data set allows us to (i) observe how the profitability evolved over time and (ii) to sample the data at any desired frequency. Third, in contrast to existing studies, we observe the best bid and ask prices which makes it possible to apply the real transaction costs at any point in time, even if these are time-varying. Fourth and finally, we apply the recently developed statistical test by Hansen (2005) for statistical inference that applies multiple testing corrections for data snooping (Harvey et al., 2016). In summary, our analysis does not provide evidence that simple technical trading rules consistently generate superior returns in a context where they are argued to flourish. However, we do find evidence that when the central bank conducts a policy focusing on exchange rate stabilization, technical trading rules can generate superior returns when applied at a sufficiently high frequency. This suggests that information captured by technical trading rules during interventions are short-lived and only valuable when applied accordingly.

The remainder of the paper is organized as follows: Section 2 describes the data. Section 3 reveals the implemented trading rules and statistical tests, Section 4 provides and discusses the results and Section 5 concludes.

\section{Data}

To assess the profitability of technical trading rules in a favorable environment, we collected a long time-span of tickby-tick transaction data of the second largest BRICS-currency (Bank of International Settlement, 2013), namely the Russian Ruble versus the US Dollar. This data was gathered from the Moscow Interbank Currency Exchange (MICEX) ${ }^{1}$ and spans the period from January 2000 till June 2011 as shown in Fig. 1. It contains information on date, time rounded to the nearest second, price, Dollar-volume and Ruble-volume for every transaction. We re-sample the tick data at a 10, 15, 30 and 60 min frequency to analyze the trade-off between the short-lived value of information and higher transaction costs due to more trading.

Additionally, the data contains information on the quoted spread and therefore we can observe real transaction costs on a tick-by-tick basis. While previous research rely on estimated transaction costs, we use real transaction costs instead. Since the spread determines the profitability of trading rules, we consider taking this time-varying character into account as essential. By using the observed spread we thus account for intraday patterns in the spread, changes in market liquidity and variations in the spread across exchange rate regimes. The upper panel in Table 1 displays how the spread decreases over time while the lower panel displays spread summary statistics across exchange rate regimes. The spread is most tight for the dual currency band regime which lasted from 2005 till 2010. The pre-2005 managed floating regime has a spread that is almost twice as large as for the subsequent regimes which is attributable to lower liquidity during that sample period.

\section{Trading rules and test design}

\subsection{Technical trading rules}

In line with literature, we test for the presence of technical trading rule profitability based on two technical trading rules most popular among practitioners (Taylor and Allen, 1992) and most widely investigated in research (Park and Irwin, 2007). The first is one of the most popular in practice while at the same also one of the most vastly tested in academic research (Park and Irwin, 2007). In short, moving averages trading rules provide buy (sell) signal whenever the short moving average crosses the long moving average from below (above). The second applied popular trading rule in practice is an oscillator called RSI (Park and Irwin, 2007). The indicator values of the RSI swing between 0 and 100 and it is used to

\footnotetext{
1 MICEX is the largest exchange in Russia and Eastern Europe. For foreign exchange, MICEX centralizes country-wide domestic RUB-USD trading on one single platform. This platform has been jointly developed with Reuters and provides similar trading features as for the Reuters or EBS (Electronic Brokerage Systems) trading platform.
} 


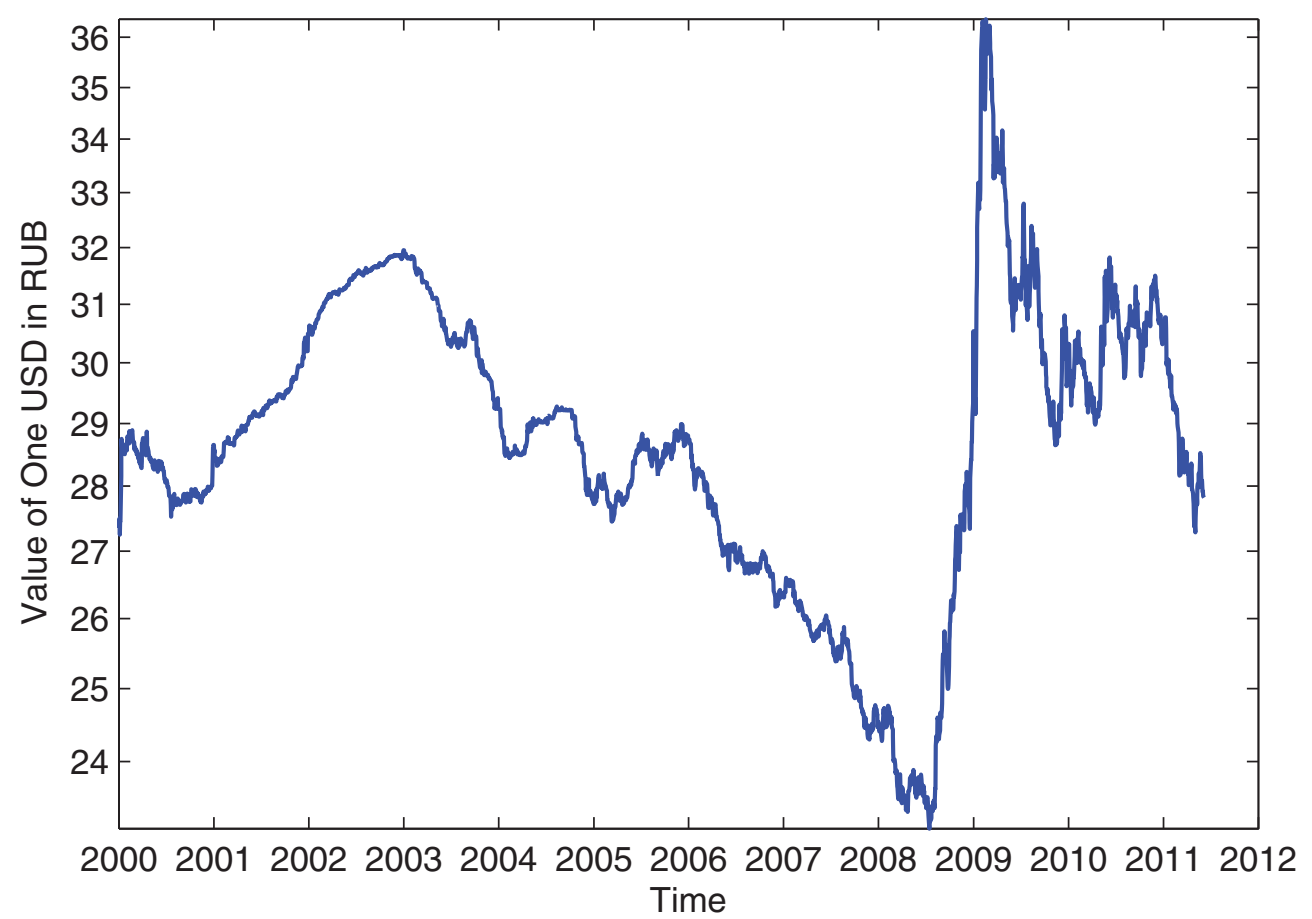

Fig. 1. Exchange rate RUB-USD. This figure displays the value of 1 USD in RUB plotted on the $y$-axis in log scale from 2000 till June 2011.

Table 1

Summary statistics bid-ask spreads.

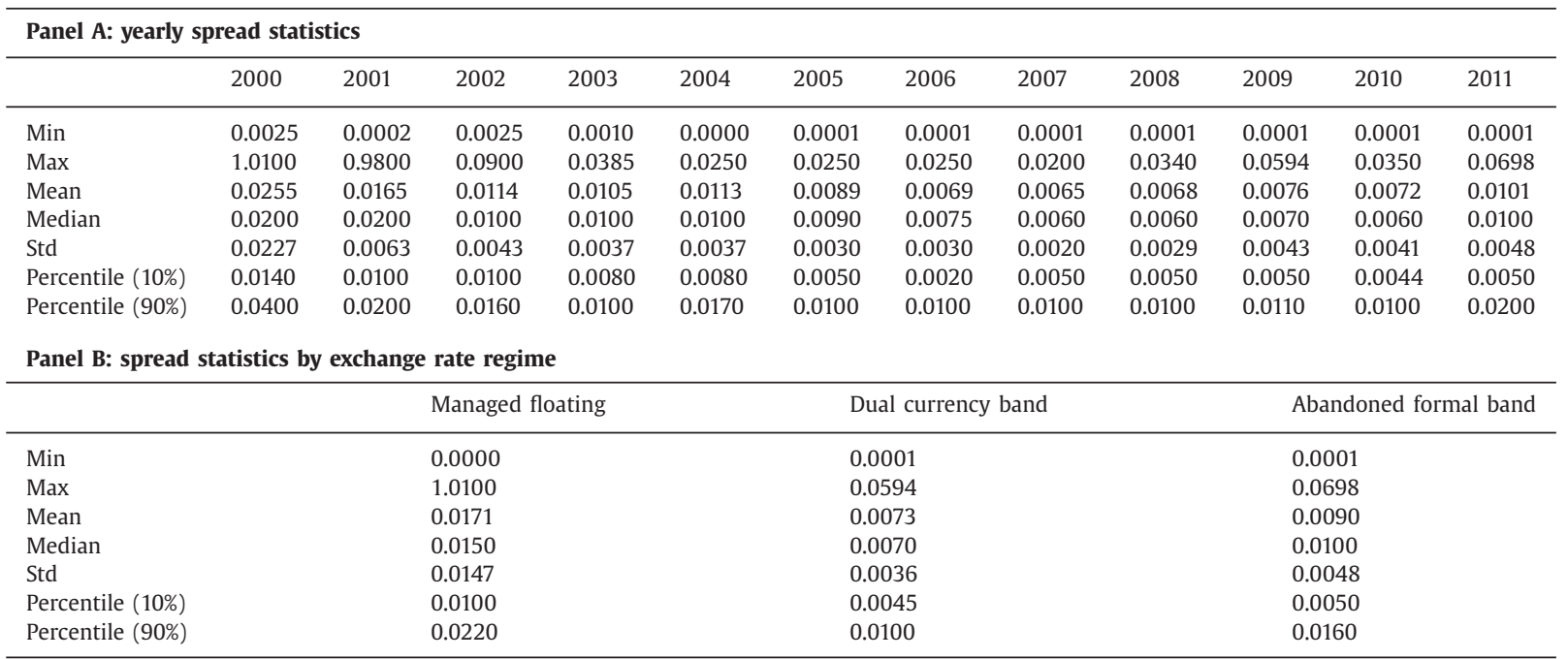

This table provides summary statistics of the quoted spread for every year and for every exchange rate policy separately using tick-by-tick data.

pinpoint overbought and oversold periods for a given security. The higher (lower) the current value of the RSI, the more it is overbought (oversold). In total we apply 4950 moving average and 3069 RSI trading rules as shown in Table 2. We focus on these 2 trading rules since we expect that their long lasting popularity among practitioners may be the result of their sound performance.

\subsection{Returns and transaction cost}

In a next step, we calculate the trading rule returns as the logarithmic difference of two consecutive trading prices possibly adjusted with the current observed spread conditional on having a trading signal.

$$
r_{k, t+1}=\left(\ln \left[P_{t+1}+h s_{t+1} \cdot S_{k, t+1}\right]-\ln \left[P_{t}+h s_{t} \cdot S_{k, t}\right]\right) \cdot D_{k, t}
$$


Table 2

Overview technical trading rules parameterizations.

\begin{tabular}{|c|c|c|c|c|c|c|c|c|c|c|c|c|}
\hline \multicolumn{13}{|c|}{ Panel A: moving average parameters } \\
\hline Short term MA lag & 1 & 1 & 1 & 1 & 1 & 2 & 2 & 2 & $\ldots$ & 98 & 98 & 99 \\
\hline Long term MA lag & 2 & 3 & 4 & ... & 100 & 3 & 4 & 5 & $\ldots$ & 99 & 100 & 100 \\
\hline \multicolumn{13}{|c|}{ Panel B: RSI parameters } \\
\hline Lower bound & 10 & 10 & 10 & 10 & 11 & 11 & 11 & 11 & $\ldots$ & 40 & 40 & 40 \\
\hline Upper bound & 90 & 90 & 90 & 90 & 89 & 89 & 89 & 89 & $\ldots$ & 60 & 60 & 60 \\
\hline Lag & 2 & 3 & $\ldots$ & 100 & 2 & 3 & $\ldots$ & 100 & $\ldots$ & 2 & $\ldots$ & 100 \\
\hline
\end{tabular}

This tables presents the various trading rule parameterizations for the moving average (Panel A) and the RSI (Panel B) trading rule.

where $r_{k, t}$ is the $k$ th return at time $t+1, P_{t}$, the mid-price at time $t, h s$ the observed half-spread, $S_{k, t}$ is the trading rule's (new) trading rule signal to buy or sell, and $D_{k, t}$ the $k$ th (existing) trading rule trading position at time $t$. This setting allows us to capture both the long run market evolution that contributes to lower spreads as well as temporary spread increases due to uncertainty or liquidity scarcity. Our research employs recent and time-varying spread data on a less liquid and more volatile exchange rate which stands in contrast to previous literature that estimates transaction costs in the nineties for major currencies and consecutively employs fixed transaction costs ranging from $0.03 \%$ to $0.08 \%$ (Bessembinder, 1994; Neely et al., 1997; Cheung and Chinn, 2001).

\section{3. $R C$ and SPA test}

To accommodate for data snooping as a result of the various parameterizations (White, 2000; Harvey et al., 2016), we employ the "superior predictive ability" test of Hansen (2005) which tests whether the best trading rule has predictive power over a benchmark taking into account the full universe of tested trading rules. This test is based on the "reality check" test of White (2000). First, we calculate the performance statistic, $f_{k, t}$, as shown in Eq. (2), where $b_{t}$ represents the benchmark return at time $t$, to assess the hypothesis that the best trading rule from the pool of various trading rules did not significantly outperform the benchmark: $H_{0}: \max _{k=1 \rightarrow L}\left\{E\left(f_{k}\right)\right\} \leq 0$.

$$
f_{k, t}=r_{k, t}-b_{t}
$$

Hansen (2005) argues that the $p$-values from the "reality check" test of White (2000) are easily inflated by adding new poor models to the universe of the tested models. Therefore, he modifies the test statistic through studentization which enables comparison of the models in terms of units of standard deviation.

$$
T^{S P A}=\max \left[\max _{k=1 \rightarrow L} \frac{\sqrt{N} \cdot \overline{f_{k}}}{\hat{\sigma}_{k}}, 0\right]
$$

Additionally, he proposes to construct a data dependent null distribution to ensure that the influence from the poor alternative models is reduced. The Hansen (2005) solution therefore compares the average return over the benchmark to a certain threshold as shown in Eq. (5).

$$
T_{i}^{S P A}=\max \left[\max _{k=1 \rightarrow L} \frac{\sqrt{N} \cdot \bar{Z}_{k, i}}{\hat{\sigma}_{k}}, 0\right]
$$

with

$$
\bar{Z}_{k, i}=\bar{f}_{k, i}-h_{x}\left(\bar{f}_{k}\right)
$$

where $h_{x}$ equals either, $h_{c}, h_{l}$, or $h_{u}$ representing the consistent, lower bound, and upper bound SPA $p$-values.

$$
\begin{aligned}
& h_{c}\left(\bar{f}_{k}\right)=\left\{\begin{array}{lll}
\bar{f}_{k} & \text { if } \quad \bar{f}_{k} \geq-\sqrt{\frac{\hat{\sigma}_{k}^{2}}{N} \cdot 2 \cdot \log \log N} \\
0 & \text { if } \quad \bar{f}_{k} \leq-\sqrt{\frac{\hat{\sigma}_{k}^{2}}{N} \cdot 2 \cdot \log \log N}
\end{array}\right. \\
& h_{l}\left(\bar{f}_{k}\right)=\max \left(0, \bar{f}_{k}\right) \\
& h_{u}\left(\bar{f}_{k}\right)=0
\end{aligned}
$$


Table 3

Overview results trading rules before transaction costs.

\begin{tabular}{|c|c|c|c|c|c|c|c|c|c|c|c|c|c|}
\hline & Year & 2000 & 2001 & 2002 & 2003 & 2004 & 2005 & 2006 & 2007 & 2008 & 2009 & 2010 & 2011 \\
\hline \multirow[t]{7}{*}{60 minutes } & Trading rule & RSI & MA & RSI & MA & RSI & RSI & RSI & RSI & MA & MA & RSI & RSI \\
\hline & Parameters & $18,70,30$ & 75,76 & $2,63,37$ & 17,29 & $2,61,39$ & $2,65,35$ & $2,70,30$ & $2,62,38$ & 2,73 & 3,5 & $41,65,35$ & $7,84,16$ \\
\hline & Transactions & 7 & 9 & 267 & 9 & 509 & 591 & 497 & 491 & 37 & 379 & 25 & 17 \\
\hline & Return & $10.23 \%$ & $6.03 \%$ & $3.44 \%$ & $6.49 \%$ & $10.38 \%$ & $19.83 \%$ & $9.32 \%$ & $10.57 \%$ & $24.48 \%$ & $36.58 \%$ & $23.69 \%$ & $10.30 \%$ \\
\hline & $c$ & 0.195 & 0.029 & 0.037 & 0.191 & 0.010 & 0.000 & 0.200 & 0.104 & 0.203 & 0.094 & 0.225 & 0.517 \\
\hline & $l$ & 0.169 & 0.022 & 0.029 & 0.146 & 0.010 & 0.000 & 0.162 & 0.080 & 0.147 & 0.075 & 0.191 & 0.454 \\
\hline & $u$ & 0.195 & 0.032 & 0.044 & 0.191 & 0.010 & 0.000 & 0.204 & 0.109 & 0.204 & 0.094 & 0.226 & 0.517 \\
\hline \multirow[t]{7}{*}{30 minutes } & Trading rule & RSI & MA & RSI & MA & RSI & RSI & RSI & RSI & MA & MA & MA & MA \\
\hline & Parameters & $18,70,30$ & 75,76 & $2,63,37$ & 31,57 & $2,62,38$ & $2,63,37$ & $2,72,28$ & $2,60,40$ & 11,41 & 6,8 & 4,9 & 4,5 \\
\hline & Transactions & 7 & 9 & 279 & 9 & 1015 & 1253 & 1023 & 1159 & 87 & 581 & 535 & 449 \\
\hline & Return & $10.23 \%$ & $6.03 \%$ & $3.69 \%$ & $8.75 \%$ & $19.04 \%$ & $26.44 \%$ & $14.25 \%$ & $11.15 \%$ & $22.72 \%$ & $49.84 \%$ & $27.14 \%$ & $13.30 \%$ \\
\hline & $c$ & 0.188 & 0.030 & 0.022 & 0.022 & 0.000 & 0.000 & 0.006 & 0.083 & 0.348 & 0.003 & 0.160 & 0.250 \\
\hline & $l$ & 0.165 & 0.022 & 0.019 & 0.015 & 0.000 & 0.000 & 0.003 & 0.070 & 0.255 & 0.002 & 0.134 & 0.204 \\
\hline & $u$ & 0.188 & 0.031 & 0.023 & 0.022 & 0.000 & 0.000 & 0.006 & 0.085 & 0.349 & 0.003 & 0.163 & 0.250 \\
\hline \multirow[t]{7}{*}{15 minutes } & Trading rule & RSI & RSI & RSI & MA & RSI & RSI & RSI & RSI & MA & MA & MA & MA \\
\hline & Parameters & $2,60,40$ & $2,60,40$ & $2,60,40$ & 61,100 & $2,60,40$ & $3,60,40$ & $2,68,32$ & $2,62,38$ & 75,76 & 19,20 & 6,18 & 9,10 \\
\hline & Transactions & 555 & 675 & 619 & 9 & 2163 & 2125 & 2399 & 2505 & 255 & 765 & 535 & 669 \\
\hline & Return & $12.76 \%$ & $11.94 \%$ & $6.97 \%$ & $9.40 \%$ & $32.16 \%$ & $40.45 \%$ & $20.12 \%$ & $18.69 \%$ & $21.85 \%$ & $48.75 \%$ & $30.02 \%$ & $12.93 \%$ \\
\hline & $c$ & 0.167 & 0.000 & 0.000 & 0.020 & 0.000 & 0.000 & 0.000 & 0.000 & 0.459 & 0.005 & 0.090 & 0.379 \\
\hline & $l$ & 0.152 & 0.000 & 0.000 & 0.015 & 0.000 & 0.000 & 0.000 & 0.000 & 0.385 & 0.005 & 0.073 & 0.312 \\
\hline & $u$ & 0.168 & 0.000 & 0.000 & 0.021 & 0.000 & 0.000 & 0.000 & 0.000 & 0.460 & 0.005 & 0.091 & 0.379 \\
\hline \multirow[t]{7}{*}{10 minutes } & Trading rule & RSI & RSI & RSI & MA & RSI & RSI & RSI & RSI & MA & MA & MA & MA \\
\hline & Parameters & $2,61,39$ & $2,60,40$ & $2,60,40$ & 2,88 & $2,60,40$ & $2,60,40$ & $2,62,38$ & $2,64,36$ & 47,48 & 28,29 & 10,24 & 17,32 \\
\hline & Transactions & 901 & 1037 & 1007 & 23 & 3319 & 4495 & 4265 & 3821 & 619 & 945 & 631 & 163 \\
\hline & Return & $20.58 \%$ & $16.81 \%$ & $11.60 \%$ & $8.56 \%$ & $58.53 \%$ & $68.66 \%$ & $37.94 \%$ & $28.05 \%$ & $21.40 \%$ & $52.54 \%$ & $29.65 \%$ & $14.71 \%$ \\
\hline & $c$ & 0.000 & 0.000 & 0.000 & 0.058 & 0.000 & 0.000 & 0.000 & 0.000 & 0.558 & 0.004 & 0.110 & 0.197 \\
\hline & $l$ & 0.000 & 0.000 & 0.000 & 0.041 & 0.000 & 0.000 & 0.000 & 0.000 & 0.437 & 0.003 & 0.088 & 0.155 \\
\hline & $u$ & 0.000 & 0.000 & 0.000 & 0.062 & 0.000 & 0.000 & 0.000 & 0.000 & 0.560 & 0.004 & 0.111 & 0.202 \\
\hline
\end{tabular}

This table provides based on a zero return benchmark without considering transaction costs the best trading rule, its corresponding parameters, number of transactions, returns and consistent, lower and upper $p$-values for the first traded contract over all considered trading frequencies. Trading rule returns that are significantly profitable at $10 \%$ or better based on the consistently $p$-value are displayed in bold. Results at a 5 min frequency are in line with the reported results and available upon request.

\section{Results}

We start our discussion with the results, as shown in Table 3, based on a zero return benchmark without incorporating any transaction costs applying the SPA-test using a 1000 bootstraps and an average block length of $5 .^{2}$ From this table we can state that an increase in the trading frequency at which technical trading rules are performed has an advantageous effect on both the realized return and on its significance. In absence of transaction costs, we find that technical trading rules can exploit the market's incomplete and lagged information processing, especially in very short terms. Specifically, we find that at a 60 -min trading frequency, the consistent $p$-values are significant at a $10 \%$ level of significance for 5 out of 12 years. When we increase the trading frequency up to 30-min intervals, the number of significant values increase to 8 at a $10 \%$ significance level from which 4 remain even significant at $1 \%$ significance level. At 15 -min intervals, the results become even stronger. In this case, technical trading rule returns have outperformed the zero return benchmark in 9 out of 12 years. At the highest frequency, a 10-min trading frequency, again 9 out of 12 yearly results are significantly positive at a $10 \%$ significance level. Moreover, the previous result further improves in terms of a further reduction of the $p$-values.

Next to these results, we also find that in tendency the number of transactions increases when the trading frequency is shortened. Therefore, the results could be biased and not representative for a real trading environment. To accommodate this problem, we apply transaction costs gathered from the observed bid-ask spread in our subsequent analysis. Overall we find that, incorporating the transaction costs deteriorate the best trading rule return to a great extent, as shown in Table 4 . As expected, imposing transactions costs based on the quoted spread largely reduces the trading rule returns. Specifically, we find at a 60 -min trading frequency that the consistent $p$-values are significant at a $10 \%$ level of significance for only 1 out of 12 years. When we increase the frequency up to 30-min intervals, the number of significant values increase to 3 at $10 \%$ significance level, whereas on a 15 -min intervals, the results deteriorate. In this case, only 2 technical trading rules are found having significantly outperformed the zero return benchmark. At the 10-min trading level, the results improve again with a total of 4 significant trading rule returns. We conclude that the lack of incorporating transaction costs in

\footnotetext{
2 This resembles to setting the parameter $q$ equal to 0.2 in the stationary bootstrap of Politis and Romano (1994). Our results remain robust when using alternative average block lengths. Moreover, Sullivan et al. (1999) set $q$ equal to 0.1 and perform 500 bootstraps, they report that their results are insensitive to the choice of the block length parameter.
} 
Table 4

Overview results trading rules after transaction costs.

\begin{tabular}{|c|c|c|c|c|c|c|c|c|c|c|c|c|c|}
\hline & Year & 2000 & 2001 & 2002 & 2003 & 2004 & 2005 & 2006 & 2007 & 2008 & 2009 & 2010 & 2011 \\
\hline \multirow[t]{7}{*}{60 minutes } & Trading rule & MA & MA & MA & MA & MA & RSI & RSI & MA & MA & RSI & RSI & RSI \\
\hline & Parameters & 81,85 & 44,63 & 30,62 & 17,29 & 58,76 & $2,77,23$ & $51,71,29$ & 46,91 & 2,73 & $68,68,32$ & $41,65,35$ & $7,84,16$ \\
\hline & Transactions & 23 & 5 & 5 & 9 & 19 & 497 & 1 & 11 & 37 & 5 & 25 & 17 \\
\hline & Return & $5.83 \%$ & $5.69 \%$ & $2.23 \%$ & $6.21 \%$ & $5.04 \%$ & $10.01 \%$ & $8.25 \%$ & $10.06 \%$ & $23.53 \%$ & $33.82 \%$ & $23.18 \%$ & $9.63 \%$ \\
\hline & $c$ & 0.891 & 0.065 & 0.420 & 0.239 & 0.386 & 0.296 & 0.336 & 0.151 & 0.262 & 0.172 & 0.275 & 0.603 \\
\hline & $l$ & 0.757 & 0.033 & 0.255 & 0.166 & 0.219 & 0.177 & 0.217 & 0.109 & 0.170 & 0.135 & 0.223 & 0.475 \\
\hline & $u$ & 0.936 & 0.152 & 0.673 & 0.241 & 0.662 & 0.389 & 0.415 & 0.184 & 0.265 & 0.174 & 0.290 & 0.617 \\
\hline \multirow[t]{7}{*}{30 minutes } & Trading rule & MA & MA & MA & MA & RSI & RSI & RSI & RSI & MA & RSI & RSI & RSI \\
\hline & Parameters & 80,89 & 44,63 & 30,62 & 31,57 & $18,90,10$ & $3,74,26$ & $13,90,10$ & $15,86,14$ & 11,41 & $99,66,34$ & $7,90,10$ & $13,90,10$ \\
\hline & Transactions & 23 & 5 & 5 & 9 & 5 & 659 & 1 & 9 & 87 & 9 & 57 & 1 \\
\hline & Return & $5.47 \%$ & $5.69 \%$ & $2.23 \%$ & $8.47 \%$ & $5.74 \%$ & $14.56 \%$ & $6.10 \%$ & $10.38 \%$ & $20.22 \%$ & $37.15 \%$ & $23.12 \%$ & $7.12 \%$ \\
\hline & $c$ & 0.928 & 0.064 & 0.425 & 0.042 & 0.477 & 0.027 & 0.865 & 0.135 & 0.513 & 0.131 & 0.380 & 0.969 \\
\hline & $l$ & 0.810 & 0.032 & 0.231 & 0.021 & 0.236 & 0.020 & 0.660 & 0.082 & 0.333 & 0.097 & 0.289 & 0.870 \\
\hline & $u$ & 0.966 & 0.146 & 0.702 & 0.044 & 0.816 & 0.070 & 0.946 & 0.196 & 0.547 & 0.134 & 0.411 & 0.983 \\
\hline \multirow[t]{7}{*}{15 minutes } & Trading rule & RSI & MA & MA & MA & RSI & RSI & RSI & RSI & MA & MA & RSI & RSI \\
\hline & Parameters & $20,66,34$ & 16,53 & 66,100 & 61,100 & $21,90,10$ & $8,61,39$ & $18,90,10$ & $27,81,19$ & 24,83 & 12,15 & $8,83,17$ & $33,71,29$ \\
\hline & Transactions & 27 & 13 & 5 & 9 & 5 & 889 & 1 & 9 & 87 & 669 & 217 & 17 \\
\hline & Return & $4.88 \%$ & $4.64 \%$ & $2.97 \%$ & $9.12 \%$ & $5.59 \%$ & $20.65 \%$ & $7.03 \%$ & $10.32 \%$ & $18.58 \%$ & $32.39 \%$ & $19.77 \%$ & $9.26 \%$ \\
\hline & $c$ & 0.982 & 0.399 & 0.292 & 0.034 & 0.583 & 0.001 & 0.771 & 0.160 & 0.681 & 0.290 & 0.657 & 0.825 \\
\hline & $l$ & 0.837 & 0.217 & 0.166 & 0.014 & 0.307 & 0.001 & 0.566 & 0.077 & 0.447 & 0.206 & 0.503 & 0.585 \\
\hline & $u$ & 0.992 & 0.766 & 0.701 & 0.065 & 0.961 & 0.006 & 0.937 & 0.335 & 0.745 & 0.322 & 0.780 & 0.908 \\
\hline \multirow[t]{7}{*}{10 minutes } & Trading rule & RSI & MA & MA & RSI & RSI & RSI & RSI & RSI & MA & MA & RSI & MA \\
\hline & Parameters & $22,65,35$ & 51,89 & 32,100 & $12,90,10$ & $7,62,38$ & $8,60,40$ & $11,64,36$ & $43,75,25$ & 30,97 & 16,25 & $18,83,17$ & 17,32 \\
\hline & Transactions & 55 & 17 & 11 & 1 & 813 & 1447 & 753 & 9 & 123 & 505 & 45 & 163 \\
\hline & Return & $5.49 \%$ & $5.47 \%$ & $3.26 \%$ & $8.44 \%$ & $9.87 \%$ & $21.01 \%$ & $10.67 \%$ & $11.61 \%$ & $18.18 \%$ & $32.99 \%$ & $20.59 \%$ & $8.08 \%$ \\
\hline & $c$ & 0.985 & 0.316 & 0.280 & 0.067 & 0.066 & 0.001 & 0.171 & 0.084 & 0.742 & 0.257 & 0.602 & 0.925 \\
\hline & $l$ & 0.829 & 0.143 & 0.137 & 0.033 & 0.029 & 0.001 & 0.109 & 0.050 & 0.498 & 0.178 & 0.410 & 0.691 \\
\hline & $u$ & 0.999 & 0.778 & 0.777 & 0.155 & 0.628 & 0.030 & 0.503 & 0.264 & 0.830 & 0.285 & 0.758 & 0.984 \\
\hline
\end{tabular}

This table provides based on a zero return benchmark with considering transaction costs the best trading rule, its corresponding parameters, number of transactions, returns and consistent, lower and upper $p$-values for the first traded contract over all considered trading frequencies. Trading rule returns that are significantly profitable at $10 \%$ or better based on the consistently $p$-value are displayed in bold. Results at a 5 min frequency are in line with the reported results and available upon request.

our previous analysis mostly explains the previous found increase in significant returns. ${ }^{3}$ Overall, the results are far less outspoken compared the analysis above.

Our findings based on the lower trading frequencies thus comply with Kuang et al. (2014) who show that the profitability of technical trading rule returns for various emerging FX markets are illusionary after taking into account transaction costs and data snooping biases. Nevertheless, in the case of the highest trading frequency, we find that on occasion - from 2003 till 2007 - technical trading rules yield superior returns. This suggests that information captured by technical trading rules are short-lived and are only valuable when applied accordingly. Moreover, we find this result only during times when the Russian central bank imposed a managed floating regime and from 2005 onwards a dual-currency basket (Central Bank of the Russian Federation, 2013) aimed at reducing the volatility of the exchange rate. Taking these two findings together, our results comply with the literature suggesting that central bank interventions may create profit opportunities for technical trading rules (LeBaron, 1999; Saacke, 2002; Szakmary and Mathur, 1997), but only exploitable when trading at a very high pace.

\section{Conclusion}

In our study we conclude that initially our results support the existence opportunities for technical trading strategies in the most favorable setting as suggested by literature (Park and Irwin, 2007). However by revisiting the impact of transaction cost on technical trading rule profits through the use of real, time-varying transaction costs, we find that trading rule returns deteriorate and do not significantly outperform the benchmark. Nevertheless, we do find some evidence that when the central bank conducted a policy of stabilizing the exchange rate, technical trading rules can generate superior returns when applied at a sufficiently high trading frequency. This suggests that information captured by technical trading rules are shortlived and are only valuable when applied accordingly.

\section{References}

Bank of International Settlement, 2013. Triennial Central Bank Survey of Foreign Exchange and Derivatives Market Activity in 2013. Bank of International Settlement.

\footnotetext{
${ }^{3}$ We find similar results when assessing based on a buy-and-hold benchmark both with and without adjustment for transaction costs.
} 
Bessembinder, H., 1994. Bid-ask spreads in the interbank foreign exchange markets. J. Financ. Econ. 35 (3), $317-348$.

Bessembinder, H., Chan, K., 1995. The profitability of technical trading rules in the Asian stock markets. Pacific-Basin Financ. J. 3 (2), $257-284$.

Central Bank of the Russian Federation, 2013. The history of the bank of Russia's exchange rate policy. In: Bank of International Settlement (Ed.), Sovereign Risk: A World Without Risk-free Assets?, vol. 73. Bank for International Settlements, pp. 293-299.

Chang, Y.-H., Chan, C.-C., Chiang, Y.-C., 2014. Volume information and the profitability of technical trading. Asia-Pacific J. Financ. Stud. 43 (2), $249-272$.

Cheung, Y.-W., Chinn, M.D., 2001. Currency traders and exchange rate dynamics: a survey of the US market. J. Int. Money Financ. 20 (4), 439-471.

Cheung, Y.-W., Chinn, M.D., Marsh, I.W., 2004. How do UK-based foreign exchange dealers think their market operates? Int. J. Financ. Econ. 9 (4), $289-306$.

Gehrig, T., Menkhoff, L., 2006. Extended evidence on the use of technical analysis in foreign exchange. Int. J. Financ. Econ. 11 (4), $327-338$.

Hansen, P.R., 2005. A test for superior predictive ability. J. Bus. Econ. Stat. 23 (4), 365-380.

Harvey, C.R., Liu, Y., Zhu, H., 2016. ... and the cross-section of expected returns. Rev. Financ. Stud. 29 (1), 5-68.

Kuang, P., Schröder, M., Wang, Q., 2014. Illusory profitability of technical analysis in emerging foreign exchange markets. Int. J. Forecast. 30 (2), $192-205$.

LeBaron, B., 1999. Technical trading rule profitability and foreign exchange intervention. J. Int. Econ. 49 (1), $125-143$.

Lo, A.W., 2004. The adaptive markets hypothesis. J. Portf. Manag. 30 (5), 15-29.

Lui, Y.-H., Mole, D., 1998. The use of fundamental and technical analyses by foreign exchange dealers: Hong Kong evidence. J. Int. Money Financ. 17 (3), $535-545$.

Lyons, R.K., 2001. The Microstructure Approach to Exchange Rates. MIT Press.

Malkiel, B., 1996. A Random Walk Down Wall Street. W. W. Norton, New York.

Menkhoff, L., 1997. Examining the use of technical currency analysis. Int. J. Financ. Econ. 2 (4), 307-318.

Menkhoff, L., Taylor, M.P., 2007. The obstinate passion of foreign exchange professionals: technicalanalysis. J. Econ. Lit. 45 (4), $936-972$.

Neely, C., Weller, P., Dittmar, R., 1997. Is technical analysis in the foreign exchange market profitable? A genetic programming approach. J. Financ. Quant. Anal. 32 (4), 405-426.

Neely, C.J., Weller, P.A., 2013. Lessons from the evolution of foreign exchange trading strategies. J. Bank. Financ. 37 (10), $3783-3798$.

Oberlechner, T., 2001. Importance of technical and fundamental analysis in the European foreign exchange market. Int. J. Financ. Econ. 6 (1), 81-93.

Olson, D., 2004. Have trading rule profits in the currency markets declined over time? J. Bank. Financ. 28 (1), $85-105$.

Park, C.-H., Irwin, S.H., 2007. What do we know about the profitability of technical analysis? J. Econ. Surv. 21 (4), 786-826.

Politis, D.N., Romano, J.P., 1994. The stationary bootstrap. J. Am. Stat. Assoc. 89 (428), 1303-1313.

Qi, M., Wu, Y., 2006. Technical trading-rule profitability, data snooping, and reality check: evidence from the foreign exchange market. J. Money Credit Bank 38 (8), 2135-2158.

Saacke, P., 2002. Technical analysis and the effectiveness of central bank intervention. J. Int. Money Financ. 21 (4), $459-479$.

Schulmeister, S., 2006. The interaction between technical currency trading and exchange rate fluctuations. Financ. Res. Lett. 3 (3), $212-233$.

Schulmeister, S., 2009. Profitability of technical stock trading: Has it moved from daily to intraday data? Rev. Financ. Econ. 18 (4), $190-201$.

Sullivan, R., Timmermann, A., White, H., 1999. Data-snooping, technical trading rule performance, and the bootstrap. J. Financ. 54 (5), $1647-1691$.

Szakmary, A.C., Mathur, I., 1997. Central bank intervention and trading rule profits in foreign exchange markets. J. Int. Money Financ. 16 (4), 513-535.

Taylor, M., Allen, H., 1992. The use of technical analysis in the foreign exchange market. J. Int. Money Financ. 11 (3), $304-314$.

White, H., 2000. A reality check for data snooping. Econometrica 68 (5), 1097-1126. 